those who responded partially evolved to liver cirrhosis, with a similar follow-up time in both groups (105 vs 113 months). 5 of the 6 patients who did not have a biochemical response developed liver cirrhosis. 7 of the 13 patients with cirrhosis $(54 \%)$ already presented clinical or histological data of cirrhosis in the initial evaluation

Conclusions: PBC patients have frequently other autoimmune diseases such as Autoimmune Hepatitis, Sjögren syndrome or Scleroderma so we must actively seek the presence of these pathologies. The treatment with ursodeoxycholic seems to be useful in all patients but it is important to make an early diagnosis Disclosure of Interest: None declared

DOI: 10.1136/annrheumdis-2018-eular.7546

\section{AB1144 $\quad$ HISTOLOGY OF ROSAI-DORFMAN DISEASE IN A SUBSET OF PATIENTS WITH ERDHEIM-CHESTER DISEASE: A DISTINCT ENTITY MAINLY DRIVEN BY MAP2K1}

J. Razanamahery ${ }^{1}$, E. Diamond ${ }^{2}$, F. Cohen-Aubart ${ }^{1}$, P. Karl-Heinz ${ }^{3}$, F. Charlotte ${ }^{4}$, Z. Helias-Rodzewicz ${ }^{5}$, A. Dogan ${ }^{6}$, O. Abdel-Wahab ${ }^{6}$, B. Durham ${ }^{6}$, N. Ozkaya ${ }^{6}$, Z. Amoura ${ }^{1}$, J.-F. Emile ${ }^{5}$, J. Haroche ${ }^{1} .^{1}$ Internal medecine, Pitié-Salpêtrière hospital, Paris, France; ${ }^{2}$ Neurology, Memorial Sloan Kettering Cancer Center, New York, USA $;{ }^{3}$ Neurology, Frankfurt-Cancer-Institute, Frankfurt, Germany; ${ }^{4}$ Pathology, Pitié-Salpêtrière hospital; ${ }^{5}$ Pathology service, Ambroise Paré hospital, paris, France; ${ }^{6}$ Pathology and Laboratory, Memorial Sloan Kettering Cancer Center, New York, USA

Background: Diagnosis of Erdheim-Chester disease (ECD) is based on characteristic imaging of bone, retroperitoneal and/or cardiovascular involvement. Biopsy is mandatory to exclude other diagnoses and confirm infiltration of histiocytes, but histology is not specific. ${ }^{2}$ By contrast diagnosis of Rosai-Dorfman disease (RDD), a rare histiocytosis, is based on histology, which is characterised by infiltration by CD68 +CD1 a- S100+ histiocytes with large nuclei and abundant lesions of emperipolesis. ${ }^{2}$ Up to $70 \%$ of ECD have BRAF or MAP2K1 mutations, ${ }^{3}$ which are rare in RDD.

Objectives: We investigated patients harbouring an ECD phenotype but RDD histology.

Methods: We reviewed records of ECD patients followed in Pitié-Salpêtrière hos pital (Paris, France) and Memorial Sloan Kettering Cancer Centre (New-York, NY USA) between 2007 and 2018. Biopsy samples of the patients were systematically investigated for mutations of genes of MAP kinase pathway.

Results: Among 209 patients with ECD, we found 10 (4.7\%) patients who had RDD histology. These 10 patients had typical ECD clinical and radiological presentation, in particular bones $(n=7)$, vascular $(n=5)$ and peritoneal $(n=6)$ involvements. Patients also had typical neurological involvement of ECD $(n=6)$. All patients except one had at least one biopsy with a compatible histology of ECD at diagnosis. ECD biopsies showed non-specific fibrosis $(n=5)$, foamy CD 68 + CD1 a- histiocytes $(n=3)$ and/or Touton cells $(n=1)$. Biopsies disclosing RDD histology were performed during the course of the disease involving testes $(n=5)$, stomach $(n=1)$, tibia $(n=2)$, cheek $(n=1)$ and omentum $(n=1)$. All tissues showed lympho-plasmocytic infiltrate with large histiocytes infiltration. Histiocytes were CD68 +CD1 a- S100 +with large nuclei and abundant lesions of emperipolesis. Five patient harboured MAP2K1 mutation and one patient had PIK3CA mutation. None of the patients had BRAF mutation.

Conclusions: Some patients with ECD may also present the iconic histological lesions described by Rosai and Dorfman. Overlap forms of such distinct histiocytoses between ECD and RDD is mainly driven by MAP2K 1 but not by BRAF.

\section{REFERENCES:}

[1] Diamond EL, Dagna L, Hyman DM, Cavalli G, Janku F, Estrada-Veras J, et al. Consensus guidelines for the diagnosis and clinical management of Erdheim-Chester disease. Blood. 2014;124:483-92.

[2] Emile J-F, Abla O, Fraitag S, Horne A, Haroche J, Donadieu J, et al. Revised classification of histiocytoses and neoplasms of the macrophagedendritic cell lineages. Blood. 2016;127:2672-81.

[3] Haroche J, Charlotte F, Arnaud L, von Deimling A, Hélias-Rodzewicz Z, Hervier B, et al. High prevalence of BRAF V600E mutations in ErdheimChester disease but not in other non-Langerhans cell histiocytoses. Blood. 2012;120:2700-3.

Disclosure of Interest: None declared DOI: 10.1136/annrheumdis-2018-eular.4917

\section{$\mathrm{AB} 1145$ \\ ACUTE POSTERIOR MULTIFOCAL PLACOID PIGMENT EPITHELIOPATHY: CLINICAL PATTERN AND} MANAGEMENT OF 79 PATIENTS

J. Álvarez Troncoso ${ }^{1}$, A. Schlinker Giraud ${ }^{2}$, F. Arnalich Fernández ${ }^{1}$, Á.

Robles. Marhuenda ${ }^{1} .{ }^{1}$ Internal Medicine; ${ }^{2}$ Ophthalmology, Hospital Universitario La Paz, Madrid, Spain

Background: Acute Posterior Multifocal Placoid Pigment Epitheliopathy (APMPPE) is an uncommon inflammatory disease causing acute-onset chorioretinal bilateral disease. It typically affects the posterior pole of both eyes leading to visual blurring or scotomas. Although it is thought to be benign, APMPPE has been associated with central nervous system (CNS) manifestations: cerebral vas culitis, meningoencephalitis and cerebral vascular disease.

Objectives: The aim of this study was to define clinical features, systemic manifestations, treatment and outcomes of a review of 79 patients with APPMPE.

Methods: We retrospectively analysed the epidemiology, potential triggers, prodromes, clinical data, ophthalmological study, extraocular manifestations, treatment and outcomes of 79 patients collected through an extensive review of the literature from the first description of Gass JD up to the present time.

Results: A total of 79 patients were reviewed ( 47 male). Mean age at diagnosis was 30 years (with a range of 8 to 58 years old). 27 patients $(34.2 \%)$ presented with a previous triggering being flu-like illness the most frequent. ${ }^{15}$ However, the complete serological study was only requested in 28 patients (and the immunolog ical study just in 22) Median time from trigger to overt APPMPE was 9 days. Main clinical symptoms were: decreased visual acuity/blurry vision (100\%), headache $(51.8 \%)$ and photophobia (12.2\%). Average decreased visual acuity was $13 / 20$ APPMPE is defined by the presence of multiple white-yellowish plaques in funduscopy, and early hypofluorescent areas with late hyperfluorescence in fluorescein angiography. The fundus was pathological and compatible with APPMPE in all cases (100\%), as was fluorescein angiography in those that had been performed (59). CNS involvement appeared in up to $50.6 \%$ (40 patients). The CNS manifes tations were divided into language disorders (11 patients), motor deficit, ${ }^{20}$ sensory deficit $^{20}$ and other CNS manifestations. ${ }^{23}$ The mean time from visual deficit to neurological manifestations was approximately 2 weeks. Cerebrospinal fluid was studied in 37 patients, with a predominance of lymphocytic pleocytosis (mean of $46 \mathrm{cells} / \mathrm{mm} 3$ ) and elevated proteins (mean of $111 \mathrm{mg} / \mathrm{dl}$ ). Within the neuroimag ing studies carried out $(58)$ up to $69.7 \%$ were pathological. 67 patients $(84.8 \%)$ received treatment with corticosteroids. 14 patients $(17.7 \%)$ also received other immunosuppressants (mainly azathioprine and cyclophosphamide), especially if CNS involvement. Regarding the evolution, 55 patients $(69.6 \%)$ presented improvement, $12(15.2 \%)$ relapsed and 6 (7.5\%) died due to APPMPE.

Conclusions: APPMPE is a rare inflammatory disease which primarily affects the retina. However, the CNS involvement could be more frequent than what is classically described. Also, it seems that there might be a trigger effect either inflammatory or infectious. Steroids and immunosuppressants should be considered in patients with CNS involvement from the beginning.

\section{REFERENCE:}

[1] Case D, Seinfeld J, Kumpe D, Folzenlogen Z, Jones W, Simpson J, et al. Acute posterior multifocal placoid pigment epitheliopathy associated with stroke: a case report and review of the literature. J Stroke Cerebrovasc Dis 2015;24:e295-e302.

Disclosure of Interest: None declared DOI: 10.1136/annrheumdis-2018-eular.3777

\section{AB1146 14 THE ASSOCIATION OF COMMON MEFV GENE MUTATIONS WITH AXIAL SPONDYLARTHRITIS IN FMF PATIENTS: A RETROSPECTIVE STUDY}

K. Ayar ${ }^{1}$, E.K. Ozturk ${ }^{2}$, O. Yesiloz ${ }^{2} .{ }^{1}$ Rheumatology; ${ }^{2}$ Physical therapy and Rehabilitation, University of Health Sciences, Bursa Yuksek Ihtisas Training and Research Hospital, BURSA, Turkey

Background: Familial Mediterranean fever (FMF) is an autoinflammatory dis ease seen with autosomal recessive inheritance and is characterised by recurren and self-limiting attacks with peritonitis, pleuritis, arthritis or fever alone. The association of spondylarthritis and FMF is reported in some studies. There are few studies evaluating the association of MEFV gene mutations with axial spondylarthritis in FMF patients.

Objectives: The aim of this study is to identify patients with FMF associated spondylarthritis retrospectively and to compare the frequency of common MEFV gene mutations in FMF patients with and without axial spondylarthritis.

Methods: We have reviewed 138 charts of FMF patients. The data of 116 patients (70 female, 46 male) who met the diagnosis of FMF with Tel Hashomer classification criteria and have the results of MEFV gene mutation were examined. Patients' age, sex, MEFV gene mutations were recorded. The presence of 
inflammatory back pain (IBP) obtained from rheumatological system questionnaire in the patients' charts were recorded. The $x$-ray and MR images of sacroiliac joint registered in the PACS system were evaluated by a Rheumatologist. Patients with inflammatory low back pain and sacroiliitis detected by X-ray or MR were included in the FMF with axial spondylarthritis (FMF-SPA) group and others to FMF group. The frequency of MEFV gene mutations were compared between two groups.

Results: The frequency of M694V, M680I, V726A, E148Q and R202Qare $82.4 \%$, $19.6 \%, 16.7, \% 10.8 \%$ and $16.7 \%$ respectively in FMF group and $78.6 \%, 21.4 \%$, $14.3 \%, 21.4 \%$ and $28.6 \%$ respectively in FMF-AS group. There was no significant difference between groups $(p=0.716, p=1.000, p=1.000, p=0.373$ and $p=0.279$ respectively). The frequency of $\mathrm{M} 694 \mathrm{~V}$ homozygotes and heterozygotes mutations were $27.5 \%$ and $21.6 \%$ respectively in FMF group and $35.7 \%$ and $7.1 \%$ respectively in FMF-SPA group and difference between groups was not significant $(p=0.537, p=0.296$ respectively).

Abstract AB1146 - Table 1. The characteristics and MEFV gene mutations of FMF patient with spondylarthritis

\begin{tabular}{|c|c|c|c|c|c|}
\hline & $\begin{array}{l}\text { Age, } \\
\text { years }\end{array}$ & Sex & IBP & $\begin{array}{l}\text { Sacroiliitis } \\
\text { X-ray/MR }\end{array}$ & MEFV mutations \\
\hline 1 & 34 & $\mathrm{~F}$ & + & $-1+$ & M694V/M680I \\
\hline 2 & 41 & $F$ & + & $-1+$ & M694V/M694V \\
\hline 3 & 31 & $F$ & + & $+/ N D$ & E148Q/R202Q \\
\hline 4 & 56 & $M$ & + & $+/ \mathrm{ND}$ & $\mathrm{M} 680 \mathrm{I} / \mathrm{E} 148 \mathrm{Q}$ \\
\hline 5 & 49 & $M$ & + & $+/ \mathrm{ND}$ & M694V/- \\
\hline 6 & 47 & $M$ & + & $+/ N D$ & M694V/E148Q \\
\hline 7 & 22 & $M$ & + & $+/ N D$ & $\mathrm{M} 694 \mathrm{~V} / \mathrm{M} 680 \mathrm{I}$ \\
\hline 8 & 22 & $\mathrm{~F}$ & + & $+/ \mathrm{ND}$ & M694V/M694V \\
\hline 9 & 39 & $F$ & + & $+/ N D$ & M694V/M694V \\
\hline 10 & 30 & $M$ & + & $+/ N D$ & M694V/M694V \\
\hline 11 & 37 & $M$ & + & $+/ N D$ & M694V/M694V/R202Q/R202Q \\
\hline 12 & 41 & $\mathrm{~F}$ & + & $+/ \mathrm{ND}$ & M694V/R202Q/A744S \\
\hline 13 & 24 & $F$ & + & $-1+$ & V726A/K695R \\
\hline 14 & 31 & $\mathrm{~F}$ & + & $+/ N D$ & M694V/V726A/R202Q \\
\hline
\end{tabular}

ND: Not done, IBD: inflammatory back pain

Conclusions: The frequency of common MEFV gene mutations in this study is not different between FMF patients with and without axial spondylarthritis. Increased frequency of axial spondylarthritis in FMF patients may not be associated with MEFV gene mutations.

\section{REFERENCES:}

[1-] Akar S, Soysal O, Balci A, Solmaz D, Gerdan V, Onen F, Tunca M, Akkoc $\mathrm{N}$. High prevalence of spondyloarthritis and ankylosing spondylitis among familial Mediterranean fever patients and their first-degree relatives: further evidence for the connection. Arthritis Res Ther. 2013 Jan 28;15(1):R21. doi: 10.1186/ar4154.

[2] - Livneh A, Langevitz P, Zemer D, Zaks N, Kees S, Lidar T, Migdal A, Padeh S, Pras M. Criteria for the diagnosis of familial Mediterranean fever. Arthritis Rheum. 1997 Oct;40(10):1879-85

Disclosure of Interest: None declared

DOI: 10.1136/annrheumdis-2018-eular.6721

\begin{tabular}{|l|l}
\hline AB1147 & EVOLUTIONARY STUDY OF 45 CASES OF \\
UNDIFFERENTIATED NEGATIVE HLA B27 \\
SERONEGATIVE OLIGOARTHRITIS
\end{tabular}

L. Expósito Pérez ${ }^{1}$, J.J. Bethencourt Baute ${ }^{2}$, S. Bustabad Reyes $2 .{ }^{1}$ HOSPITAL UNIVERSITARIO DE CANARIAS, San Cristóbal de La Laguna, Spain;

${ }^{2}$ Rheumatology, Hospital Universitario de Canarias, San Cristóbal de La Laguna, Spain

Background: The prognosis of patients with undifferentiated arthritis may vary from self-limited to severe destructive rheumatoid arthritis. Early diagnosis is important, specially in seronegative oligoarthritis in order to start a treatment as early as possible.

Objectives: To describe the evolution of patients older than 16 years diagnosed with negative HLA B27 seronegative oligoarthritis without axial involvement.

Methods: We retrospectively studied 45 patients ( 23 women, 22 men) with negative HLA B27 seronegative oligoarthritis without axial involvement who debuted between 1985 and 1990 and who did not meet the criteria for any of the rheumatic diseases at the time of debut: rheumatoid arthritis (AR), psoriatic arthropathy (PsA), spondyloarthropathy, enteropathic arthritis, reactive arthritis, microcrystalline arthritis or connective tissue disease.
Results: The mean age at onset of oligoarthritis was 42.2 years (range 17-66). The mean follow-up time was 13.7 years (range 1-32). In its evolution, a definitive diagnosis was reached in $21(46.6 \%)$ patients, with the mean time between debut and diagnosis being 5.47 years (range 1-25): 8 AR, 4 APs (3 with involvement) peripheral and 1 mixed), 2 undifferentiated spondyloarthritis, enteropathic arthritis, 5 gouty arthropathies and one SLE. In the case of RA, the diagnosis was made on an average of 4.8 years after the debut (range 1-16); the RF was positive in 4 patients a mean of 7.6 years (range $3-11$ ) after the debut, and the anti-CCP were positive in 3 of the patients with positive RF. Within PsA, one developed skin psoriasis, another psoriatic onicopathy at 4 years after debut and 2 continue with out skin involvement but with a family history of psoriasis, all met CASPAR criteria From the other 24 patients $(53.3 \%)$, only 3 patients $(12.5 \%)$ continued to be followed up, with an average of 21.3 years (range 18-26) without meeting the criteria that allow us to define diagnosis. With the rest of the patients $(40.8 \%)$, followed for an average of 4.5 years, a diagnosis was not achieved by resolution of the clinical picture or loss of follow-up.

Conclusions: In our series, $46.6 \%$ of the patients with a diagnosis of negative HLA B27 seronegative oligoarthritis began to meet diagnostic criteria for rheumatic disease after a mean time of 5.47 years, with RA being the most frequent diagnosis $(38 \%)$ after an average of 4.8 years after the arthritis onset.

\section{REFERENCE:}

[1] K.N. Verpoort, H. van Dongen, C.F. Allaart, R.E.M. Toes, F.C. Breedveld T.W.J. Huinzinga. Undifferentiated arthritis-Disease course assessed in several inception cohorts. Clin Exp Rheumatol 2004;22 (Suppl.35):S12 S17.

Disclosure of Interest: None declared

DOI: 10.1136/annrheumdis-2018-eular.6004

\section{AB1148 BIOLOGICAL TREATMENT OF NON ISCHAEMIC OPTIC NEURITISASSOCIATED TO IMMUNE-MEDIATED INFLAMMATORY DISEASES. MULTICENTER STUDY}

L.C. Domínguez Casas ${ }^{1}$, V. Calvo-Río ${ }^{1}$, O. Maríz-Alonso ${ }^{2}$, A. Blanco ${ }^{3}$, J. Narvaez ${ }^{4}$, S. Castañeda ${ }^{5}$, E. Vicente ${ }^{5}$, S. Romero Yuste ${ }^{6}$, R. Demetrio-Pablo ${ }^{7}$ N. Vegas-Revenga ${ }^{1}$, M. Gonzalez-Gay ${ }^{1}$, R. Blanco ${ }^{1} .{ }^{1}$ Rheumatology, HUMV, Santander, ${ }^{2}$ Rheumatology; ${ }^{3}$ Ophtalmology, H. Donostia, San Sebastian; ${ }^{4}$ Rheumatology, H. Bellvitge, Barcelona; ${ }^{5}$ Rheumatology, H. La princesa, Madrid ${ }^{6}$ Rheumatology, H. Pontevedra, Pontevedra; ${ }^{7}$ Ophtalmology, HUMV, Santander, Spain

Background: Non ischaemic optic neuritis (NION) is a severe inflammation of the optic nerve that may lead to blindness. It can be primary or associated to immune-mediated inflammatory diseases (IMIDs). The treatment of the NION is based on systemic corticosteroids and conventional immunosuppressive drugs.

Objectives: To assess the efficacy of the biological treatment in refractory NION to conventional treatment.

Methods: Multicenter study of 8 patients diagnosed with NION refractory to systemic corticosteroids and at least one conventional immunosuppressive drug.

The main outcomes were visual acuity (VA) and OCT of the optic nerve and the ganglionar cells. Comparisons were made between baseline and the 1st week, 1 st and 6th month and 1st year. (STATISTICA, StatSoft Inc. Tulsa, Oklahoma, USA).

Results: We studied 8 patients (12 affected eyes) $(4+/ 4 \AA$ ); mean age of 34.37 \pm 13.30 years. The underlying diseases were SLE $(n=1)$, neuromyelitis optica $(n=1)$, neuroretinitis $(n=1)$, relapsing polychondritis $(n=1)$, idiopathic $(n=2)$ and Behçet's disease $(n=2)$.

Before biological treatment and besides oral corticosteroids patients had received intravenous (IV) methylprednisolone boluses $(n=6)$, cyclosporine A (CyA) $(n=1)$, ciclophosphamide $(n=2)$, micophenolate $(n=2)$, hydroxycloroquine $(n=1)$, methotrexate $(M T X)(n=4)$ and azathioprine $(A Z A)(n=2)$.

Biological treatment was based on rituximab $(n=2)$ ( 2 IV. doses of 1 g/very 2 weeks and every 6 months), adalimumab $(n=2) 40 \mathrm{mg} /$ week, tocilizumab $(n=2)$ $8 \mathrm{mg} / \mathrm{kg} / 2-4$ weeks and infliximab $(\mathrm{n}=2) 5 \mathrm{mg} / \mathrm{kg}$ at 0,2 and 6 week and then every 8 weeks.

The characteristics of the 8 patients are shown in the TABLE

After biological treatment we observed an improvement in the ocular parameters: VA $[0.60 \pm 0.33$ to $0.76 \pm 0.41, p$ : 0.04$]$, OCT of the optic nerve [130.63 \pm 60.54 to $102.60 \pm 8.17, \mathrm{p}: 0.1]$ and OCT of the ganglionar cells [404.60 \pm 184.73 to 243 \pm 18.38 , p: 0.17 ] at one year. After a mean follow-up of $27 \pm 14.47$ months there were no severe adverse effects. 